\title{
Konfirmasi Patahan Permukaan Awal Berdasarkan Data Geologi dan Data Gempa Daerah Kawasan Puspiptek Serpong
}

\author{
Hadi Suntoko* ${ }^{* 1}$, Supartoyo ${ }^{2}$ \\ ${ }^{1}$ Pusat Kajian Sistem Energi Nuklir, BATAN \\ JIn. Kuningan Barat Mampang Prapatan Jakarta 12710 Indonesia \\ ${ }^{2}$ Pusat Vulkanologi Mitigasi Bencana Geologi \\ Jln. Diponegoro 57 Bandung Indonesia
}

\begin{tabular}{l}
\hline INFORMASI ARTIKEL \\
\hline Riwayat Artikel: \\
Diterima: \\
30 Juni 2016 \\
Diterima dalam bentuk revisi: \\
1 Agustus 2016 \\
Disetujui: \\
29 September 2016
\end{tabular}

Kata kunci:

Tapak RDE

Patahan kapabel

Serpong

\begin{abstract}
ABSTRAK
KONFIRMASI PATAHAN PERMUKAAN AWAL BERDASARKAN DATA GEOLOGI DAN DATA GEMPA DAERAH KAWASAN PUSPIPTEK SERPONG. Perka BAPETEN No. 8/2013 menyebutkan persyaratan bahwa tapak industri nuklir tidak boleh terdapat patahan kapabel pada radius $5 \mathrm{~km}$. Telah diketahui bahwa tapak RDE tersusun oleh batu pasir, betu lempung, konglomerat dan batu apung rework yang berumur Pliosen, terdapat kelurusan lembah sungai yang dihipotesakan sebagai patahan. Metode penelitian menggunakan identifikasi potensi patahan melalui pengamatan morfologi, remote sensing menggunakan DEM, singkapan batuan, dan interpretasi hasil seismik. Tujuan penelitian adalah untuk konfirmasi patahan kapabel di sekitar tapak radius $5 \mathrm{~km}$. Jejak penpatahanan permukaan difokuskan pada pengamatan kenampakan bentuk lahan (landform), berupa kelurusan morfologi ataupun lembah, gawir patahan (fault scarp), pergeseran atau offset (sungai maupun bukit), depresi yang terbentuk sepanjang zona patahan, saddle, pressure ridge, dan bentuk sungai serta analisis gempa. Hasil yang diperoleh menunjukkan bahwa tidak ada patahan kapabel dan tidak ada bukti patahan permukaan di sekitar tapak RDE dalam radius $5 \mathrm{~km}$.
\end{abstract}

\begin{abstract}
S
PRELIMINARY CONFIRMATION OF A SURFACE FAULTING BASED ON GEOLOGICAL AND EARTHQUAKE DATA IN THE PUSPIPTEK SERPONG AREA. BAPETEN regulation No. $8 / 2013$ present the requirement that the site of the nuclear industry should not be a fault capable in a radius of $5 \mathrm{~km}$. It is known that the RDE site composed of sandstones, claystone, conglomerates and pumice rework the age of Pliocen, there straightness river valley hypothesized as a fault. Potential faults are identified using morphological observation, remote sensing using DEM rock outcrops, and seismic intepretation results that aims to confirm capable faults in a radius of $5 \mathrm{~km}$. Traces penpatahanan surface is focused on the observation of the appearance of the terrain (landform), in the form of straightness morphology or valleys, fault scarp (fault scarp), shift or offset (river or hill), depression formed along fault zones, saddle, pressure ridge, and the shape of the river as well as earthquake monitoring. The results showed that there was no fault capable also a surface faulting that prove the presence in the RDE site radius of $5 \mathrm{~km}$.

Keywords: RDE site, capabel faults, Serpong
\end{abstract}

\section{PENDAHULUAN}

Serpong merupakan kawasan Pusat Pengembangan Ilmu Pengetahun dan Teknologi (Puspiptek) terdiri dari beberapa instansi antara lain BATAN yang didalamnya terdiri dari Reaktor Serbaguna (RSG) sebagai reaktor penelitian dan calon Reaktor Daya Eksperimental (RDE). Tapak tersebut telah melalui proses pemilihan tapak (siting) sebelumnya dan saat ini RDE akan menjadi

*Penulis korespondensi.

E-mail: hadi_suntoko@batan.go.id contoh persiapan pembangunan Pembangkit Listrik Tenaga Nuklir (PLTN) riset di Indonesia.

Dalam rangka persiapan pembangunan RDE, dilakukan evaluasi tapak untuk memperoleh karakteristik tapak dan kriteria tapak sesuai peraturan yang berlaku. Perka BAPETEN No. 08-P/Ka. BAPETEN/2013 salah satu peraturan menjadi referensi berisi tentang Evaluasi Tapak Industri Nuklir untuk Aspek Kegempaan yang merekomendasikan perlunya dilakukan evaluasi tapak terkait 
dengan pendataan geologi dan kegempaan[1]. Peraturan tersebut memuat kriteria bahwa pada radius $5 \mathrm{~km}$ dari tapak $\mathrm{RDE}$ tidak boleh ada patahan kapabel.

Menurut IAEA, patahan kapabel adalah suatu patahan yang berpotensi untuk mengakibatkan terjadinya deformasi permukaan[2]. Sementara itu menurut peraturan Kepala Badan Pengawas Tenaga Nuklir Nomor 8 tahun 2013 tentang evaluasi tapak instalasi nuklir untuk aspek kegempaan, mendefinisikan bahwa patahan atau patahan kapabel adalah suatu patahan yang mempunyai potensi signifikan untuk terjadinya pergeseran pada atau dekat permukaan tanah.

Patahan permukaan (surface faulting) merupakan sobekan permanen dari permukaan tanah akibat gerakan yang berbeda melintasi suatu patahan selama gempa[1]. Sedangkan patahan adalah struktur tektonik berupa rekahan yang telah mengalami pergeseran sehingga terjadi perpindahan antara bagianbagian yang berhadapan dengan arah yang sejajar dengan bidang rekahan[1]. Patahan (fault) merupakan retakan atau sistem retakan sepanjang batuan yang telah mengalami pergerakan[3,4]. Retakan pada batuan yang belum bergerak atau bergeser dinamakan kekar (joint). Suatu patahan dapat berupa bidang patahan atau rekahan tunggal, tetapi lebih sering membentuk lajur atau zona patahan. Zona patahan merupakan kumpulan beberapa patahan penyerta yang mengikuti atau berkaitan dengan patahan utama. Patahan dihasilkan dari deformasi yang bersifat brittle[5]. Secara kinematik patahan dapat dibedakan menjadi tiga yaitu patahan normal atau turun, geser atau mendatar dan naik. Berdasarkan tingkatan aktivitasnya, patahan dapat dibedakan menjadi tiga, yaitu patahan aktif (active fault), patahan berpotensi aktif (potential active fault), dan patahan tidak aktif (inactive fault)[6]. Patahan aktif adalah patahan yang pernah bergerak pada kurun waktu 10.000 tahun. Patahan berpotensi aktif adalah patahan yang pernah bergerak pada kurun waktu 2 juta tahun. Patahan tidak aktif adalah patahan yang belum/tidak pernah bergerak dalam kurun waktu 2 juta. Patahan kapabel merupakan parameter yang dipertimbangkan terutama dalam penempatan bangunan infrastruktur termasuk PLTN. Infrastruktur tersebut harus menghindari garis atau jalur dan zona patahan, baik patahan kapabel, patahan aktif atau patahan berpotensi aktif untuk mengurangi resiko yang mungkin timbul akibat pergerakannya.

Evaluasi tapak merupakan kegiatan penting dalam rangka mendapatkan izin tapak RDE ke BAPETEN sebagai lembaga yang memiliki regulasi nasional. Kegiatan evaluasi dimulai tahun 2014 dan diakhiri 2016 sesuai dengan Program Evaluasi Tapak (PET) dan Sistem Manajemen Evaluasi Tapak (SMET).

Kegiatan ini bertujuan untuk memperoleh informasi dan data patahan permukaan berdasarkan data elemen struktur, serta membuktikan ada tidaknya patahan dalam radius $5 \mathrm{~km}$ untuk memastikan keamanan tapak.

Lingkup kegiatan meliputi interpretasi morfologi menggunakan Digital Elevation Model (DEM), endataan sekunder/primer, konfirmasi/survei lapangan, singkapan batuan, analisis, dan kesimpulan hasil penelitian. Pada kajian ini dibatasi permasalahan pada pengumpulan data dan analisis data geologi terutama pada patahan permukaan radius $5 \mathrm{~km}$ yang diawali dengan kegiatan konfirmasi lapangan. Hasil yang diperoleh diharapkan dapat memberikan informasi yang jelas mengenai keberadaan patahan sekitar tapak.

\section{METODOLOGI}

Metode penelitian meliputi pengamatan morfologi, menggunakan analisis citra (remote sensing) jenis citra radar satelite Terra SAR$\mathrm{X}$, singkapan batuan, dan interpretasi seismik berupa gempa. Dalam analisis data dilibatkan data sekunder dan data primer.

\subsection{Morfologi Tapak}

Pengamatan morfologi diawali dari interpretasi citra radar satelit Terra SAR-X berupa DEM yang memiliki resolusi 9 meter terutama di sekitar tapak RDE Serpong hingga radius $5 \mathrm{~km}$, berupa data permukaan dengan mempelajari pola sungai, lembah topografi, gawir, dan fenomena lain yang diduga sebagai kelurusan. Morfologi merupakan bentuk bentangan alam yang menggambarkan kondisi terkini, baik kondisi yang terpengaruh oleh tektonik, patahan maupun kondisi yang tidak 
terpengaruh patahan[4]. Bentuk bentang alam yang terpengaruh oleh peristiwa tektonik maupun patahan, memberikan informasi berupa lembah, gawir patahan (fault scarp), pergeseran atau offset (sungai maupun bukit), depresi yang terbentuk sepanjang zona patahan, saddle, pressure ridge, dan bentuk sungai gawir atau tebing terjal tegak lurus, terpotong sehingga tidak menerus, berbentuk teras, terlipat dan membentuk cekungan (pond) $[7]$.

\subsection{Singkapan Batuan}

Pengamatan singkapan batuan, observasi kekar, struktur geologi, kedudukan pelapisan batuan terutama pada singkapan batuan yang segar, insitu dan mewakili kondisi batuan. Data yang diperlukan terdiri dari jenis batuan, komposisi batuan, posisi batuan dan susunan pelapisan. Untuk mempertajam interpretasi singkapan batuan diperlukan pendataan sekunder yang berasal dari peneliti terdahulu pada daerah yang sama. Data sekunder berupa data geologi, data kegempaan dapat diperoleh dari instansi terkait seperti Pusat Survei Geologi (PSG) Bandung, Badan Meteorologi dan Klimatologi dan Geofisika (BMKG) maupun dari beberapa sumber yang berhubungan dengan penelitian meliputi data geologi, dan data kegempaan.

\subsection{Interpretasi Gempa}

Interpretasi gempa menggunakan data katalog gempa yang bersumber dari BMKG dan The United States Geological Survey (USGS) dari data publikasi tahun 1900 sampai dengan tahun 2014. Suatu daerah dianggap aktif jika terdapat catatan gempa yang nilai skala magnitudonya besar, berulang dan memiliki kedalaman gempa dangkal[8]. Di samping itu katalog gempa dapat diperoleh dari peneliti terdahulu yang terkait dengan pengolahan elemen struktur geologi setempat.

Secara umum daerah penelitian memberikan informasi bahwa pola kelurusan sebelah timur sungai Cisadane dikontrol oleh jalur lemah kipas vulkanik. Kelurusan ini diprediksi merupakan jalur rekahan-rekahan permukaan yang menjadi jalur aliran air sungai dan strike kelurusan berarah barat laut tenggara[9]. Data sekunder diambil dari peneliti terdahulu dari beberapa pustaka yang terkait dengan daerah penelitian, sedangkan data primer pengamatan morfologi, morfotektonik, singkapan batuan, dan unsurunsur penpatahanan permukaan. Jejak penpatahanan permukaan akan difokuskan pada pengamatan kenampakan bentuk lahan (landform), berupa kelurusan morfologi ataupun lembah, gawir patahan (fault scarp), lembah linier (linier valley), pergeseran atau offset (sungai maupun bukit), zona muka pegunungan (mountain front), depresi yang terbentuk sepanjang zona patahan, saddle, pressure ridge, tonjolan tektonik (tectonic bulge), sungai teranyam, dan lain-lain (Gambar 1). Pengamatan bentuk lahan tersebut difokuskan pada daerah yang diperkirakan merupakan jalur atau garis patahan dan juga zona patahan.

Sebelum pengamatan lapangan, dilakukan verifikasi menggunakan metode interpretasi dengan beberapa data, yaitu data citra dengan jenis citra radar satelit Terra SAR-X berupa DEM yang menggambarkan bentang alam meliputi sungai dan morfologi permukaan. Interpretasi dan analisis DEM dilakukan menggunakan software Global Mapper untuk mempelajari pola kelurusan sungai, kelokan sungai, bentuk sungai, dan morfologi permukaan dari bentukan lahan yang dibatasi dalam radius $5 \mathrm{~km}$ dari tapak RDE Serpong. Kelokan sungai yang tajam dan morfologi sungai rapat mengindikasikan adanya struktur geologi yang bekerja dengan menandai kelurusan yang diduga akibat pengaruh tektonik. Selanjutnya kelurusankelurusan tersebut dikonfirmasi ke lapangan dengan survei geologi detail meliputi pendataan elemen struktur geologi. Pendataan lain terkait dengan patahan permukaan adalah analisis data kegempaan yang bersumber dari USGS dan BMKG (1900 hingga 2014)[10]. Hasil analisis data tersebut untuk memverifikasi data permukaan yang mengindikasikan adanya patahan permukaan maupun zona tektonik aktif.

Metode tersebut untuk mendukung kajian paleoseismologi, yaitu suatu kajian untuk mempelajari kejadian gempa bumi masa lampau menyangkut dimensi besaran, waktu dan perulangannya[6]. Metode ini pada umumnya melakukan pembuatan paritan atau trenching pada lokasi yang dicurigai sebagai jalur patahan permukaan atau patahan aktif. 


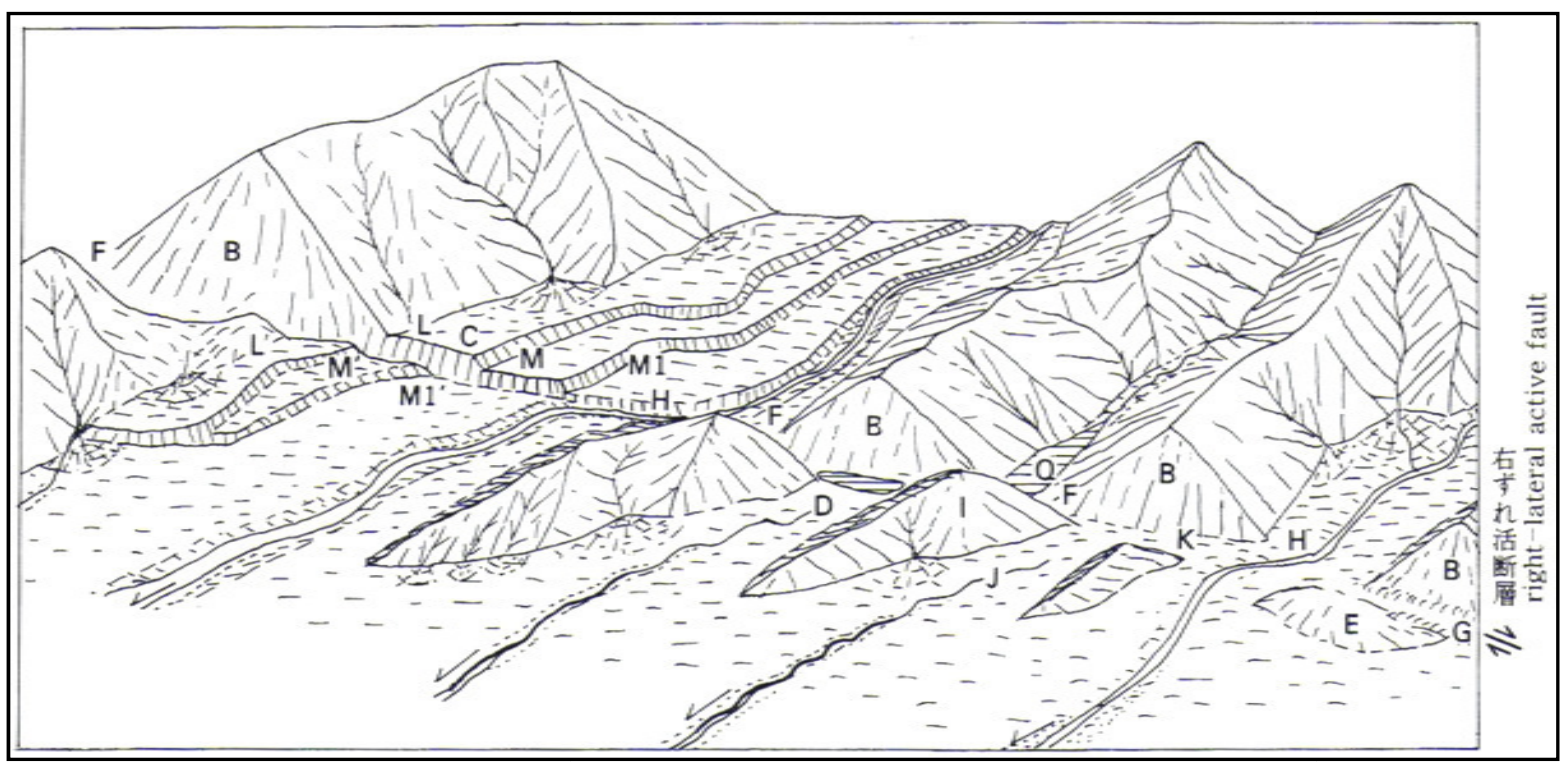

Gambar 1. Bentuk Lahan yang Terbentuk Berkaitan dengan Patahan Mendatar ke Arah Kanan[4].

Untuk menentukan lokasi paritan dilakukan kajian menggunakan metode interpretasi.

Keterangan huruf pada Gambar 1: B adalah perbukitan faset segitiga; $\mathrm{C}$ adalah gawir patahan; E adalah tonjolan tektonik/tectonic bulge; $\mathrm{F}$ adalah fault saddle, $\mathrm{G}$ adalah graben; $\mathrm{H}$ adalah pergeseran sungai;

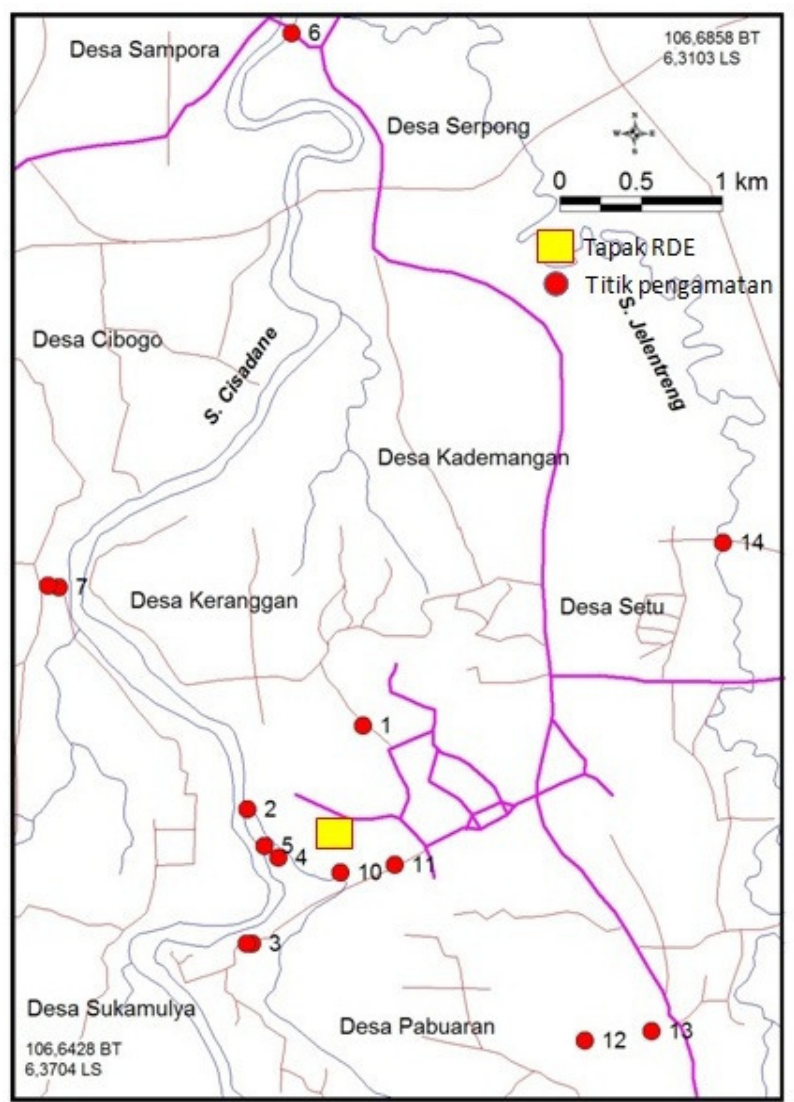

Gambar 2. Peta Tapak RDE dan Sekitarnya dan Lokasi Pengumpulan Data Geologi Radius 5 km[11].
I adalah shutter ridge; $\mathrm{J}$ adalah sungai teranyam/behaided stream; $\mathrm{K}$ adalah gap angin/wind gap; L-L' adalah pergeseran pegunungan muka; M-M' adalah pergeseran teras; Q adalah fault pond.

\subsection{Lokasi Survei}

Lokasi survei meliputi Desa Serpong, Keranggan, Pabuaran, Setu, Cibogo, Sukamulya dalam radius $5 \mathrm{~km}$ dari Puspiptek Serpong (Gambar 2). Lokasi survei dapat ditempuh menggunakan kendaraan roda dua maupun kendaraan roda empat[11].

\section{HASIL DAN PEMBAHASAN}

Berdasarkan hasil analisis citra DEM radius $5 \mathrm{~km}$, berupa pola sungai, bentuk sungai dan morfologi bentang alam menunjukkan arah pola kelurusan berarah tenggara - barat laut. Sungai yang memiliki belokan tajam mengindikasikan adanya proses struktur geologi yang bekerja di sekitarnya termasuk oleh adanya resistensi batuan[12]. Morfologi permukaan dan lembah sungai yang memiliki kelurusan kontur berupa gawir juga mengindikasikan adanya kegiatan tektonik. Melihat dan mempelajari bentuk bentang alam daerah tapak RDE dan sekitarnya secara umum mendukung keberadaan kelurusan pola sungai. 


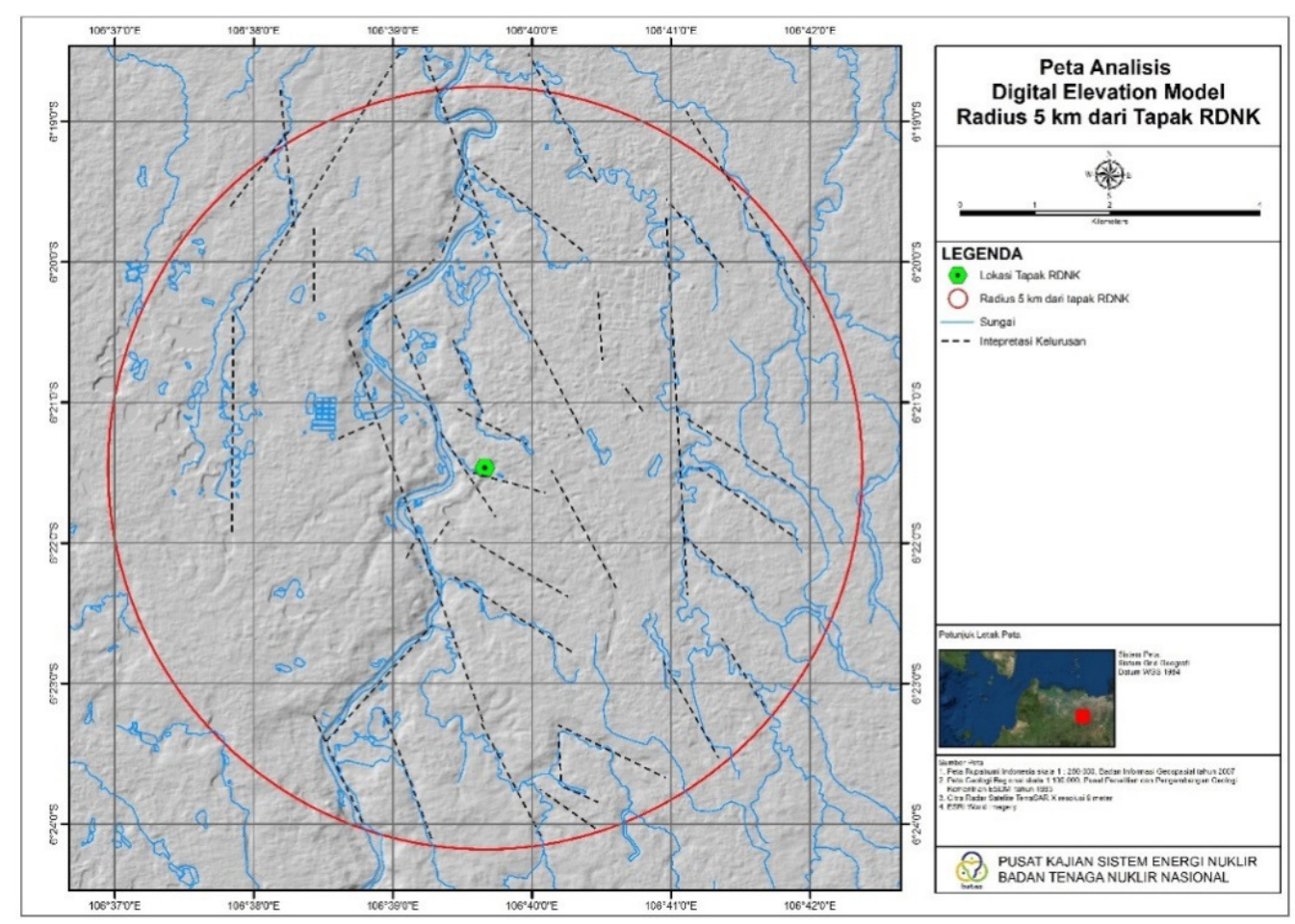

Gambar 3. Peta Analisis Citra Radar Satelit Terra SAR-X, DEM Resolusi 9 m, Radius 5 km.

Hasil interpetasi kelurusan yang dapat dilihat dari interpretasi citra DEM kemudian dilanjutkan dengan melakukan konfirmasi lapangan untuk membuktikan keberadaan kelurusan tersebut.

Survei geologi yang meliputi pengumpulan data elemen struktur geologi dilakukan guna membuktikan patahan permukaan melalui konfirmasi lapangan di sekitar tapak RDE dalam radius $5 \mathrm{~km}$. Data yang dianalisis berupa kedudukan stratigrafi, kekar, bidang sesar, dan elemen struktur geologi lainnya yang memberikan informasi singkapan batuan sebagai penyusun daerah penelitian. Secara umum tapak RDE dan sekitarnya didominasi oleh singkapan batuan berupa batu pasir, betu lempung, dan konglomerat berumur Pliosen (Tersier) yang memiliki kedudukan pelapisan N $125^{\circ}$ E/20[13]. Data kekar terdapat di beberapa titik pengamatan yaitu di pinggir sungai Cisadane N $105^{\circ} \mathrm{E} / 80^{\circ}, \mathrm{N} 173^{\circ} \mathrm{E} / 65^{\circ}$. Tidak ada data elemen struktur geologi yang signifikan untuk dapat dilakukan analisis kekar, sehingga dalam radius $5 \mathrm{~km}$ kondisi patahan permukaan dapat dikatakan nihil. Beberapa fragmen berupa fragmen batuan beku jenis andesit dan batua pung hasil produk gunung api tersingkap dalam satu pelapisan konglomerat yang merupakan rework, yaitu endapan sekunder yang terbentuk dari endapan primer yang terbawa oleh media air di suatu tempat dan diendapkan kembali serta sebagian telah membentuk soil[11].

Hasil analisis DEM dalam radius $5 \mathrm{~km}$, menunjukkan kelurusan lembah sungai dan morfologi tapak RDE berarah tenggara - barat laut (Gambar 3).

Berdasarkan kondisi lembah sungai dan topografi, kelurusan diduga sebagai patahan yang disebabkan adanya gaya kompresi berasal dari pergerakan regional[9]. Kondisi yang diduga sebagai patahan, selanjutnya dibuktikan dengan konfirmasi lapangan dan bukti lain seperti fenomena alam dari keterdapatan singkapan batuan[15]. Pendataan lapangan meliputi elemen struktur geologi, jenis batuan, kemiringan lapisan, kekar, bidang sesar, dan gores garis.

Konfirmasi lapangan difokuskan di sekitar Serpong hingga jarak sekitar $5 \mathrm{~km}$ dari tapak RDE. Pengamatan dan pendataan geologi berjumlah 14 titik lokasi pengamatan (LP). Hasil pengamatan selengkapnya ditampilkan pada Tabel 1.

Beberapa LP pengamatan yang diduga sebagai kehadiran penpatahanan permukaan adalah pada LP 4 (GWR), LP 7 (G01), LP 8 (G02), LP 9 (SINGOFSET), LP 12 (D01), LP 13 (D02). Adapun lokasi pengamatan lainnya tidak 


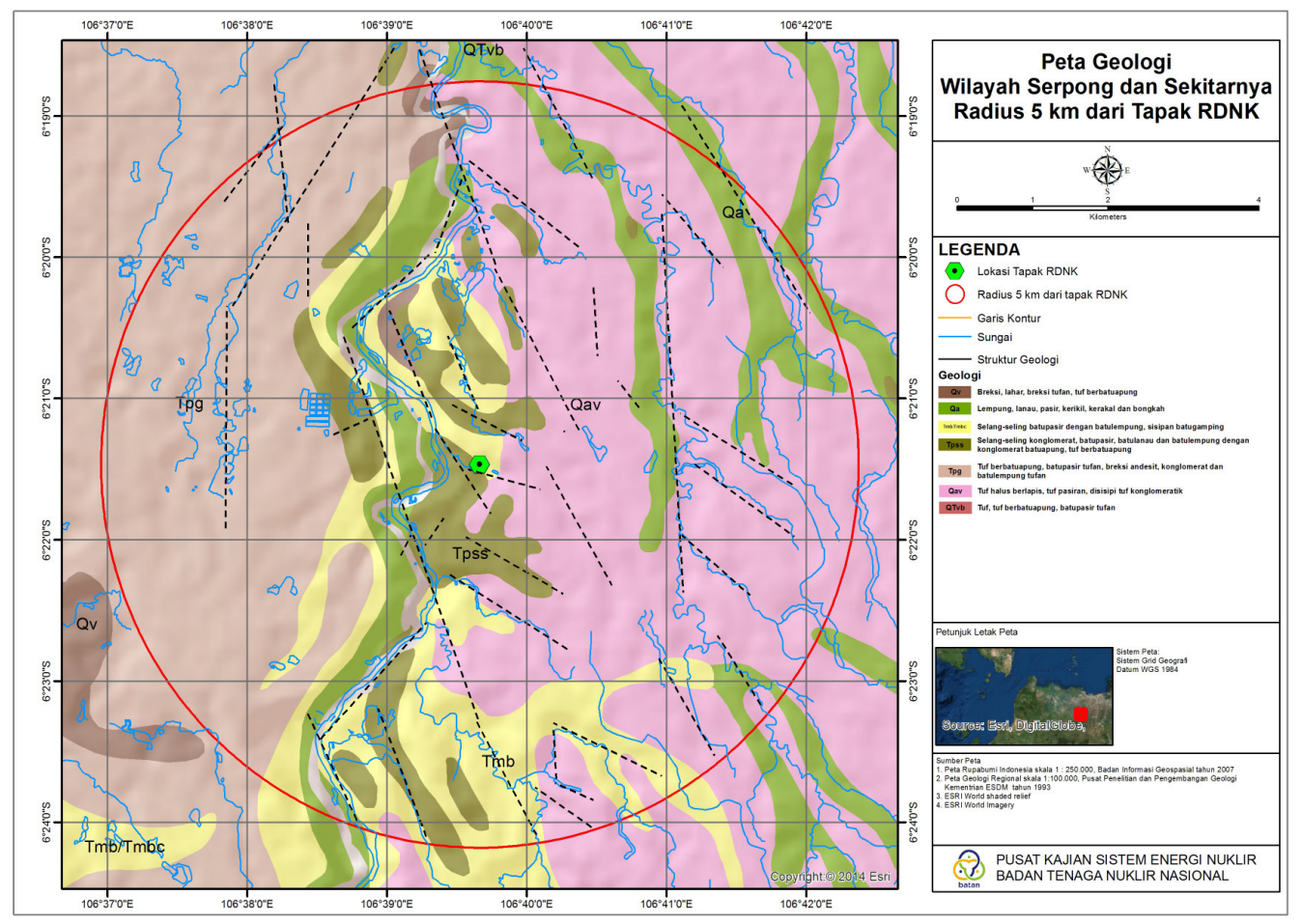

Gambar 4. Peta Geologi dan Analisis Citra DEM, Radius 5 km[14].

berkaitan dengan kemungkinan akan kehadiran penpatahanan permukaan.

Berdasarkan data lapangan pada LP 4 (GWR) terlihat adanya singkapan batu pasir, berwarna hitam, ukuran butir pasir kasar, dengan arah retakan N $105^{\circ} \mathrm{E} / 80^{\circ}$. Retakan ini mempunyai kedudukan cukup tegak, hanya bersifat lokal dan tidak menerus ke arah sungai (ke bagian barat) yaitu pada LP 5 (SCSDN) (Gambar 3).

Letak LP 7 (G01) dan LP 8 (G02) relatif berdekatan (Gambar 4). Retakan tanah yang terdapat pada batu lempung yang membentuk tanah pelapukan cukup tebal berbentuk melengkung yang merupakan ciri dari gerakan tanah. Gerakan tanah tersebut merupakan tipe rayapan. Arah gerakan tanah adalah $\mathrm{N} 105^{\circ} \mathrm{E}$ hingga $\mathrm{N} 106^{\circ} \mathrm{E}$ dan mengarah ke arah lembah. Gerakan tanah ini tidak berkaitan dengan aktivitas penpatahanan permukaan, tetapi diakibatkan oleh beberapa faktor, yaitu adanya pembebanan pada zona deplesi dan mahkota gerakan tanah (dalam hal ini kendaraan), karakteristik tanah lempung, curah hujan maupun air permukaan[5].

Pada LP 9 (SINGOFSET) terlihat singkapan pada tebing dengan dimensi panjang sekitar $28 \mathrm{~m}$ dan tinggi sekitar $13 \mathrm{~m}$ (Gambar 5). Singkapan pada LP 9 berupa lempung, pasir dan gravel. Gravel ini memperlihatkan adanya aliran, sehingga diperkirakan merupakan endapan sungai. Pada singkapan ini diduga berupa offset setempat pada batu pasir setinggi $1,5 \mathrm{~m}$. Offset tersebut meskipun memberikan kesan patahan naik, namun hanya bersifat lokal dan tidak menerus hingga ke lapisan permukaan atau lapisan di atasnya sehingga bukan offset akibat tektonik.

Offset ini diperkirakan terbentuk akibat mekanisme proses slump, sehingga bukan merupakan indikasi adanya penpatahanan permukaan[7]. Di dekat LP 9 ini terdapat danau atau depresi. Menurut keterangan dari para penambang (karena lokasi tersebut merupakan penambangan pasir dan koral), danau tersebut terbentuk akibat kegiatan penambangan pasir dan koral, dan diperkirakan terbentuk sekitar 9 tahun yang lalu.

Lokasi LP 12 (D01) dan LP 13 (D02) relatif berdekatan (Gambar 8). LP 12 dan LP 13 merupakan depresi yang tersusun oleh endapan aluvial. Suatu depresi dapat mencirikan kehadiran patahan permukaan yang terbentuk oleh diapitnya dua buah patahan. Berdasarkan pengamatan lapangan kedua depresi ini bukan terbentuk akibat proses penpatahanan, karena tidak ditemukan indikasi adanya patahan di sekitar lokasi depresi tersebut. 
Analisis untuk data regional dilakukan berdasarkan peta geologi lembar Jakarta dan Kepulauan Seribu serta peta seismotektonik daerah Selat Sunda[9,16]. Berdasarkan kenampakan peta geologi lembar Jakarta dan Kepulauan Seribu tidak terlihat adanya patahan dari peta geologi tersebut, termasuk pada lokasi dengan radius $5 \mathrm{~km}$ dari tapak RDE. Demikian juga halnya berdasarkan peta seismotektonik daerah Selat Sunda tidak terlihat adanya patahan pada radius $5 \mathrm{~km}$ dari tapak RDE[9].
Berdasarkan kenampakan morfologi daerah penelitian pada umumnya adalah dataran, dataran bergelombang, dan lembah. Morfologi tersebut tidak ada yang memperlihatkan adanya gejala akibat penpatahanan. Kelurusan DEM yang diduga patahan dilakukan konfirmasi lapangan hasilnya tidak ada bukti gawir atau dinding pelapisan yang terbentuk akibat tektonik. Jika patahan tersebut tertutup oleh aluvial tentunya terindikasi adanya patahan aktif di sekitar sungai Cisadane dalam radius $5 \mathrm{~km}$, namun

Tabel 1. Lokasi Pengamatan pada Survei Patahan Permukaan

\begin{tabular}{|c|c|c|c|c|c|c|c|}
\hline No & Kode & Tanggal & Bujur & Lintang & Tinggi & Desa & Keterangan \\
\hline 1 & BTN & 07/03/2016 & 106.6623 & -6.3496 & $53 \mathrm{~m}$ & Muncul, Tangsel & Dataran, endapan aluvial \\
\hline 2 & SCSDNE & 07/03/2016 & 106.6558 & -6.3543 & $35 \mathrm{~m}$ & Muncul, Tangsel & Endapan sungai. \\
\hline 3 & SING01 & 08/03/2016 & 106.6561 & -6.3617 & $40 \mathrm{~m}$ & $\begin{array}{c}\text { Pabuaran, G. Sindur, } \\
\text { Bogor }\end{array}$ & $\begin{array}{l}\text { Gawir akibat } \\
\text { penambangan dan } \\
\text { endapan sg. }\end{array}$ \\
\hline 4 & GWR & 08/03/2016 & 106.6575 & -6.3570 & $49 \mathrm{~m}$ & Muncul, Tangsel & $\begin{array}{c}\text { Batupasir, hitam, ukuran } \\
\text { butir pasir kasar, dengan } \\
\text { arah retakan N } 105^{\circ} \mathrm{E} / \\
80^{\circ} .\end{array}$ \\
\hline 5 & SCSDN & 08/03/2016 & 106.6568 & -6.3563 & $53 \mathrm{~m}$ & Muncul, Tangsel & Endapan sungai. \\
\hline 6 & SCDNE & 08/03/2016 & 106.6582 & -6.3113 & $47 \mathrm{~m}$ & Muncul, Tangsel & $\begin{array}{l}\text { Batupasir, coklat tua, } \\
\text { ukuran but tir pasir kasar. }\end{array}$ \\
\hline 7 & G01 & 08/03/2016 & 106.6453 & -6.3420 & $55 \mathrm{~m}$ & Muncul, Tangsel & $\begin{array}{l}\text { Gertan tipe rayapan, } \\
\text { retakan ke arah lembah. } \\
\text { Arah gerakan tanah } \mathrm{N} \\
105^{\circ} \mathrm{E} .\end{array}$ \\
\hline 8 & G02 & 08/03/2016 & 106.6447 & -6.3419 & $57 \mathrm{~m}$ & Muncul, Tangsel & $\begin{array}{l}\text { Gertan tipe rayapan, } \\
\text { retakan ke arah } \\
\text { lembah.Arah gerakan } \\
\text { tanah N } 106^{\circ} \mathrm{E} .\end{array}$ \\
\hline 9 & SINGOFSET & 09/03/2016 & 106.6558 & -6.3617 & $53 \mathrm{~m}$ & $\begin{array}{c}\text { Pabuaran, G. Sindur, } \\
\text { Bogor }\end{array}$ & $\begin{array}{c}\text { Endapan sungai dan offset } \\
\text { setempat. }\end{array}$ \\
\hline 10 & REAKTOR & 09/03/2016 & 106.6611 & -6.3578 & $52 \mathrm{~m}$ & Muncul, Tangsel & $\begin{array}{l}\text { Batupasir, kecoklatan, } \\
\text { ukuran butir pasir kasar, } \\
\text { perlapisan relatif } \\
\text { horizontal. }\end{array}$ \\
\hline 11 & IRADIATOR & 09/03/2016 & 106.66410 & -6.3573 & $72 \mathrm{~m}$ & Muncul, Tangsel & $\begin{array}{l}\text { Batupasir, kecoklatan, } \\
\text { ukuran butir pasir kasar, } \\
\text { perlapisan relatif } \\
\text { horizontal. }\end{array}$ \\
\hline 12 & D01 & 10/03/2016 & 106.6747 & -6.3671 & $79 \mathrm{~m}$ & $\begin{array}{c}\text { Pabuaran, G. Sindur, } \\
\text { Bogor }\end{array}$ & Endapan aluvial. \\
\hline 13 & D02 & 10/03/2016 & 106.6784 & -6.3666 & $76 \mathrm{~m}$ & $\begin{array}{c}\text { Pabuaran, G. Sindur, } \\
\text { Bogor }\end{array}$ & Endapan aluvial. \\
\hline 14 & SNGAI & 10/03/2016 & 106.6824 & -6.3395 & $67 \mathrm{~m}$ & Setu, Tangsel & $\begin{array}{l}\text { Batupasir, coklat tua, } \\
\text { ukuran butir pasir kasar. }\end{array}$ \\
\hline
\end{tabular}




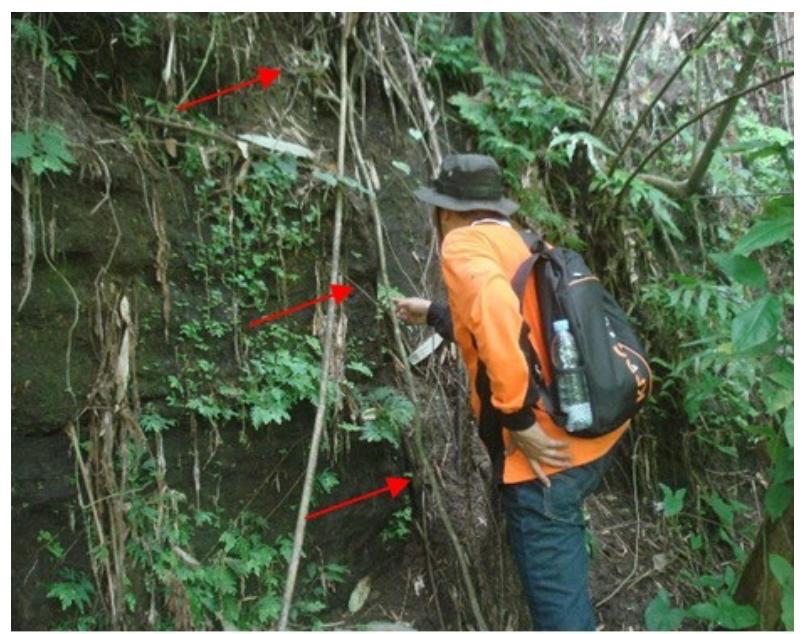

Gambar 5. Singkapan Batu Pasir dengan Arah Retakan N $105^{\circ} \mathrm{E} / 80^{\circ}$ pada LP 4 (GWR). Tanda Panah Merah

Memperlihatkan Kedudukan Retakan.

dari publikasi dan record gempa (katalog gempa) tidak ada yang menyebutkan adanya patahan[14]. Tidak ada bukti hilangnya morfologi bentuk pelapisan akibat gap antara pelapisan satu dengan pelapisan yang lainnya. Berdasarkan data elemen struktur penyerta juga tidak ditemukan adanya data yang membuktikan pergerakan suatu patahan seperti gawir patahan, seretan, kekar, gores garis. Gawir patahan adalah kelurusan morfologi yang ditandai kontur yang sama dan umumnya membentuk teras. Seretan merupakan bentuk gerakan yang ditandai jejak geser berupa goresan akibat tekanan. Kekar adalah suatu retakan pada batuan yang belum mengalami pergerakan, sedangkan gores garis adalah struktur garis yang terbentuk akibat pergerakan sesar, pada permukaan bidang sesar oleh akibat tekanan yang besar dan

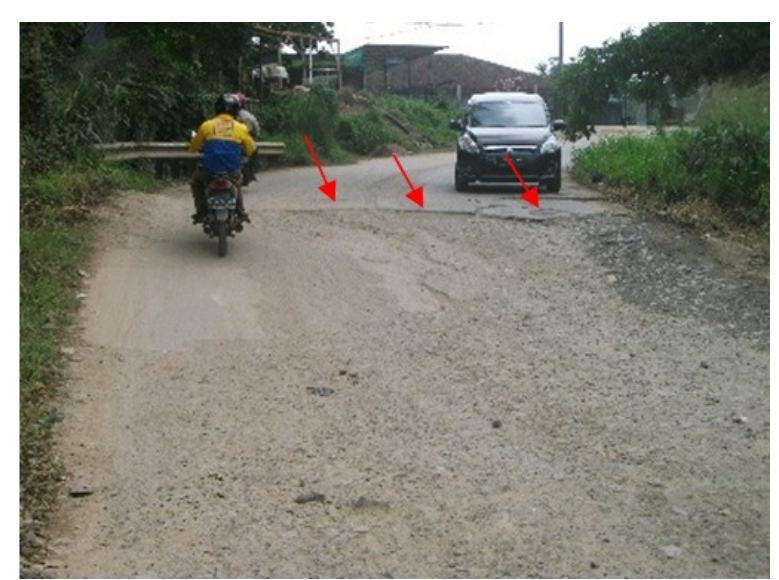

Gambar 6. Retakan Ranah (Tanda Panah Merah) Merupakan Ciri Gerakan Tanah Tipe Rayapan Akibat Beban Material di Atasnya LP 8 (G02).

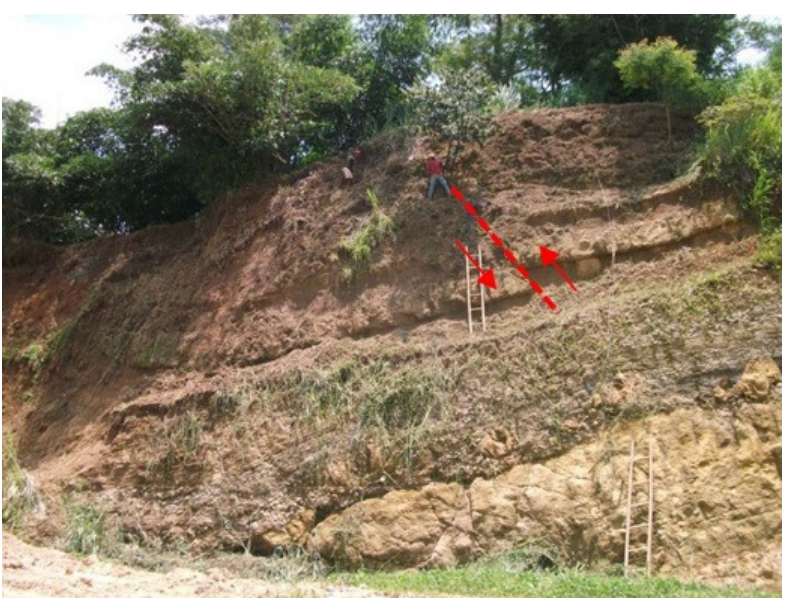

Gambar 7. Singkapan pada LP 9 (SINGOFSET) Offset Ditunjukkan Warna Merah.

permukaan bidang sesar ini menjadi licin. Kekar pada batu pasir dengan kedudukan N $105^{\circ} \mathrm{E} / 80^{\circ}$ (LP 4) tidak berkaitan dengan mekanisme penpatahanan karena terdapat hanya setempat dan tidak menerus hingga ke arah sungai (ke bagian baratnya).

Singkapan pada LP 9 yang merupakan endapan sungai dan terdapat dugaan offset setinggi $1,5 \mathrm{~m}$ pada batu pasir, tidak berkaitan dengan mekanisme penpatahanan karena terdapat hanya setempat dan tidak menerus memotong lapisan pada bagian atas dan bawahnya. Jika merupakan patahan yang berumur kuarter akibat tektonik maka offset tersebut akan memotong di semua pelapisan. Hal ini kemungkinan diakibatkan oleh proses slump yang mengakibatkan terjadinya offset setempat. Depresi yang terdapat pada LP 12

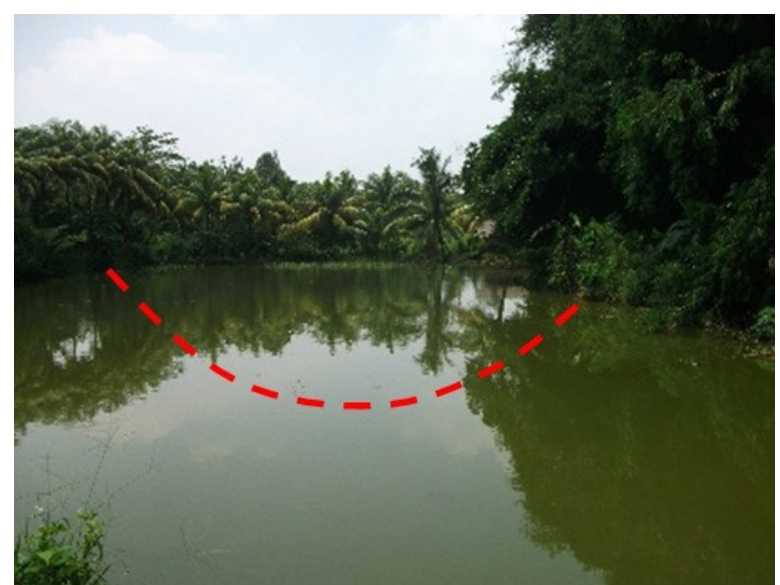

Gambar 8. Depresi yang Membentuk Danau (Warna Garis Merah) pada LP 13 (D02). 


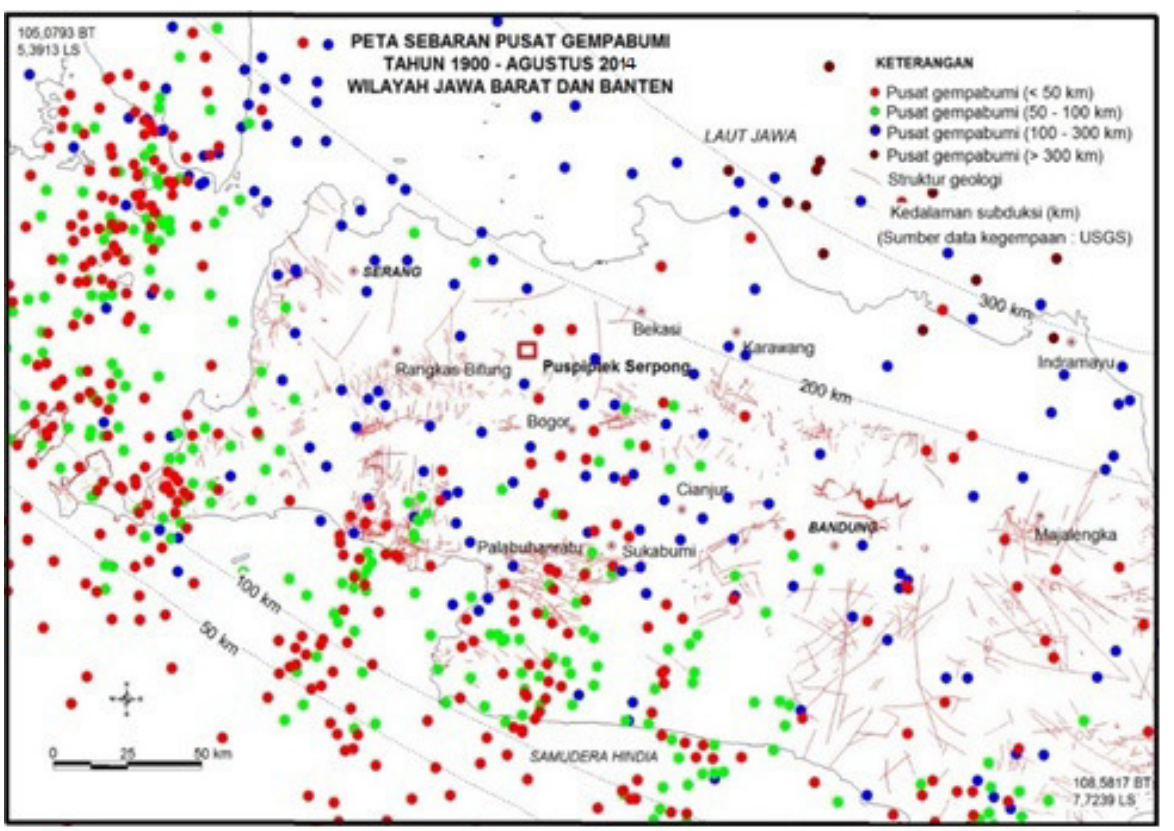

Gambar 9. Peta Sebaran Pusat Gempabumi Wilayah Banten dan Jawa Barat[17]. Tapak RDE Kotak Merah.

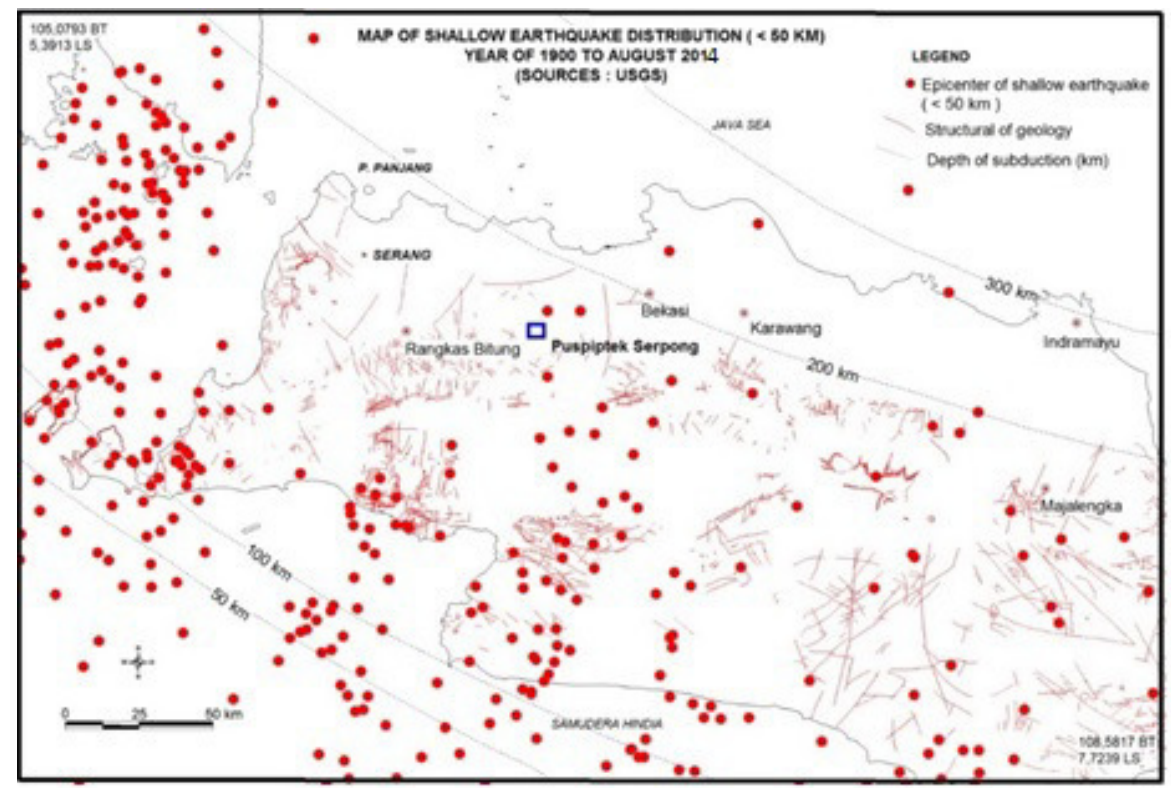

Gambar 10. Peta Sebaran Pusat Gempa Bumi Kedalaman Dangkal (Kurang dari 50 km) Wilayah Banten dan Jawa Barat[17]. Tapak RDE Kotak Biru.

dan LP 13 bukan terbentuk akibat proses penpatahanan, hal ini tidak mengindikasikan adanya patahan di sekitar lokasi. Penyebab depresi akibat kegiatan penambangan pasir dan koral oleh penduduk setempat sekitar 9 tahun lalu yang dibiarkan terbuka.

Berdasarkan data kegempaan dari katalog BMKG dan USGS tahun 1900 hingga 2014[9] pada lokasi dengan radius $5 \mathrm{~km}$ dari tapak RDE, ternyata tidak ditemukan adanya sebaran episenter gempa bumi dengan kedalaman dangkal (Gambar 9 dan 10)[10].

Hal ini juga didukung dari data sejarah kejadian gempa bumi merusak wilayah Banten, ternyata di daerah Serpong tidak tercatat adanya kejadian gempa bumi merusak paling tidak sejak tahun 1973 hingga sekarang[17]. Berdasarkan data dukung dari pemantaun gempa mikro 2015 di Serpong dan sekitarnya juga tidak menunjukkan adanya aktifitas dan 
catatan gempa terkait dengan dugaan adanya patahan di radius $5 \mathrm{~km}$.

Berdasarkan interpretasi dan analisis data yang menggunakan data geologi, seismotektonik regional, data sebaran pusat gempa bumi dan kejadian gempa bumi merusak, serta pengamatan lapangan dapat disimpulkan tidak ditemukan adanya indikasi penpatahanan permukaan pada lokasi dengan radius $5 \mathrm{~km}$ dari tapak RDE.

\section{KESIMPULAN}

Hasil konfirmasi awal di lapangan yang meliputi identifikasi potensi patahan melalui pengamatan morfologi, singkapan batuan, dan interpretasi gempa menunjukkan tidak ada patahan kapabel dan tidak ada bukti patahan permukaan di sekitar tapak RDE dalam radius $5 \mathrm{~km}$, hal ini sesuai Perka BAPETEN No. 8 tahun 2013. Hasil tersebut didasarkan dari data geologi yang meliputi kedudukan pelapisan, kenampakan bentuk lahan, kelurusan morfologi, gawir patahan serta elemen struktur geologi seperti offset, depresi, saddle, pressure ridge, dan bentuk sungai yang tidak menunjukkan bukti patahan. Sedangkan dari analisis data gempa juga tidak menunjukkan adanya catatan gempa di sekitar tapak RDE.

\section{UCAPAN TERIMA KASIH}

Ucapan terima kasih penulis sampaikan kepada Tuhan Yang Maha Esa, atas izinnya penulis dapat menyusun makalah ini dengan baik. Kedua, terima kasih penulis tujukan kepada Kepala Bidang Kajian Data Tapak (KDT), yang telah memberikan kesempatan kepada penulis untuk melakukan konfirmasi lapangan bersama tenaga ahli geologi guna membuktikan ada tidaknya patahan permukaan di sekitar tapak RDE Serpong. Terima kasih juga penulis sampaikan kepada tenaga ahli geologi dan temen teman yang telah mendukung terbentuknya makalah ini.

\section{DAFTAR ACUAN}

[1] Peraturan Kepala BAPETEN. No. 8, 2013. Evaluasi Tapak Aspek Kegempaan untuk Industri Nuklir.
Badan Pengawas Tenaga Nuklir (BAPETEN). Jakarta, Indonesia.

[2] IAEA. "Site Evaluation for Nuclear Installations". International Atomic Energy Agency (IAEA), Vienna, Austria, Safety Requirements No. NS-R-3, 2003.

[3] Katili J. A. "Tectonic Frame Work, Resources and Related Problem in Southeast Asia”. Department of Mine and Energy. Jakarta, Indonesia 1997.

[4] Keller, E.A. and Pinter, N. 2002. Active Tectonic Earthquake, Uplift and Landscape. New Jersey. Prentice hall, Upper Saddle River, 362, 338.

[5] Alshop, G.I., and Marco, S. Seismogenic Slump Folds Formed by Gravity-Driven Tectonics Down a Negligible Subaqueous Slope. Tectonophysics 605, 2013, 48-69.

[6] Huzita, K., Imaizumi, T., Kaizuka, S., Matsuda, T., Nakada, T., Okada, A., Ota, Y., Utsu, T., Yonekura, N., dan Yoshii, K. 1992. Maps of Active Faults in Japan. Tokyo: University of Tokyo Press, 73.

[7] Slump (geology). https://en.wikipedia.org/wiki/Slump_(geology), diunduh tanggal 26 April 2016.

[8] Yeats, R.S., Sieh, K., Allen, C.R.1997. The Geology of Earthquakes. Oxford University Press, 567.

[9] Soehaimi, A., Effendi, I., Djuhanda, A., Hayat, D.Z., dan Hutubessy, S. "Peta Seismotektonik Daerah Selat Sunda dan Sekitarnya, Skala 1:500.000”. Pusat Penelitian dan Pengembangan Geologi. Bandung, 2004.

[10] USGS. PDE-USGS Earthquakes Data Catalog. http://earthquake.usgs.gov/earthquakes/search. 2011, diunduh 2 Mei 2016.

[11] Marjiyono, Suntoko, H., Soehaimi, A., Ariyanto, S. dan Yuliastuti. "Kelas Soil Daerah Sekitar Rencana Tapak Reaktor Daya Eksperimental (RDE) Serpong Dari Data Mikrotremor". Jurnal Pengembangan Energi Nuklir, vol.2, 2015.

[12] Hadi Suntoko, Ari Nugroho. "Laporan Analisis Gradient Horizontal (Graviti) Untuk Konfirmasi Awal Sesar Permukaan di Tapak PLTN Banten”. Pusat Kajian Sistem Energi Nuklir, Badan Tenaga Nuklir Nasional (BATAN), Jakarta, 2012.

[13] Hadi Suntoko, Ari Nugroho. "Laporan Tinjauan Aspek Pensesaran Permukaan Regional Terhadap Keselamatan Tapak di Banten”. Pusat Kajian Sistem Energi Nuklir, Badan Tenaga Nuklir Nasional (BATAN), Jakarta 2010.

[14] Pusat Kajin Sistem Energi Nuklir (PKSEN). "Laporan Evaluasi Tapak RDE Kawasan Puspiptek Serpong 'Aspek Kegempaan'”. Badan Tenaga Nuklir Nasional (BATAN), Jakarta, 2015.

[15] Hadi Suntoko, Sunarko, Bansyah Kironi. "Laporan Pendekatan Metode Geolistrik Untuk Konfirmasi Kelurusan Sesar Permukaan Pada Kegiatan Survei Tapak Banten Tahap Penapisan”. Pusat Kajian Sistem Energi Nuklir, Badan Tenaga Nuklir Nasional (BATAN), Jakarta, 2012.

[16] Turkandi, T., Sidarto, Agustiyanto, D.A., Purbo Hadiwidjoyo, M.M. "Peta geologi lembar Jakarta dan Kepulauan Seribu Jawa”. Pusat Penelitian dan Pengembangan Geologi. Bandung, 1992.

[17] Supartoyo, Surono, dan Putranto, E.T. "Katalog Gempa Bumi Merusak Indonesia Tahun 1612 - 2014 Edisi Kelima”. Pusat Vulkanologi dan Mitigasi Bencana Geologi, Badan Geologi, Departemen Energi dan Sumber Daya Mineral, Bandung, 2014, 121. 